\title{
Proyecto educativo de centro. Una alternativa real.
}

\section{Aida Torres Speranza, Guzmán Papa de la Rosa}

\section{PRESENTACIÓN DEL PROBLEMA}

Los diagnósticos que se han realizado a nivel de nuestro sistema educativo señalan como relevante, un centralismo administrativo y pedagógico junto con una estructura de financiamiento deficitaria. Estas evidencias que afectan, en mayor y menor medida, a muchos centros educativos en la actualidad (públicos o privados) provocan que los mismos no lleguen a constituirse en una identidad convocarte e integradora de su comunidad educativa.

La investigación contemporánea radicada en los "centros", está configurando un campo nuevo y complejo de intereses prácticos, políticos y académicos. El "movimiento de escuelas eficaces", el estudio de las "escuelas ejemplares", el "diseño de secundarios efectivos", "el efec to establecimiento", y otros temas más conforman la dirección de avances.

En tal sentido, la realización efectiva de un proyec to de cambio exige considerar: a) el centro educativo como organización singular, b) la participación de los actores involucrados, c) un estilo de gestión institucional y d) un modelo pedagógico

Teniendo en cuenta estas dimensiones nos hemos preguntado cuál puede ser el sentido de la gestión y organización educativas y en qué medida contribuyen estas estructuras al desarrollo y promoción de la calidad de la educación.

Es así que nuestra hipótesis básica es que cada liceo es una organización con una identidad, una estructura y una funcionalidad propia y específica, producto de la combinación de distintos factores y dimensiones organizacionales, contextuales e institucionales

Nuestra propuesta es realizar una investigación aplicada consistente en elaborar un diagnóstico situacional a través de la valoración de los aspectos facilitadores e inhibidores para la implementación de una de las posibles alternativas reales de la actualidad para las organizaciones escolares; un PROYECTO EDUCATIVO DE CENTRO (PEC).

\section{Metodolocía}

\section{Objetivos. -}

Objetivo general: - Contribuir al mejoramiento de la gestión escolar mediante la formulación de alternativas de acción para la implementación del Proyecto Educativo de Centro.

Objetivos específicos: - Determinar los modelos empíric os que subyacen en cada uno de los subtipos de investigación.

-Identificar aspectos facilitadores e inhibidores para la implementación del Proyecto Educativo de Centro.

\section{Tipo De InVestigación:}

La investigación es de carácter aplicada en cuanto a sus fines.

Desde el punto de vista de los objetivos se trata de una primera aproximación de tipo descriptivaanalítica

Realizamos una investigación aplicada consistente en:

-el diagnóstico situacional de dos Centros Educativos de Enseñanza Secundaria (exploración de modelos empíricos) construyendo lo que llamamos situación inicial (ver diseño auxiliar de investigación). - en base a criterios teóricos compartidos sobre el Proyecto Educativo de Centro, valoramos aspectos facilitadores e inhibidores para su implementación,

- finalmente, elaboramos posibles alternativas de acción para contribuir al mejoramiento de la gestión escolar.

Criterios de selección:

El objeto de nuestro estudio es la organización escolar genéricamente denominada Liceo y que a efectos de nuestra investigación fue diferenciada en dos subtipos:

a) el liceo propiamente dicho o Liceo Público.

b) Colegio Privado. 


\section{Resultados}

A través del análisis comparativo de los modelos empíricos de los dos subtipos de investigación estudiados y en base a la valoración do los aspectos facilitadores e inhibidores para la implementación del PEC, presentamos a continuación los principales resultados obtenidos:

\section{Subtipo A.}

Centro educativo del ámbito Público, fundado en 1992

Caracterizarnos al centro como "ASISTENCIAL".

Liceo barrial localizado en una zona de marginación económica-cultural, de reciente crecimiento demográfico con población dormitorio. Entorno socio-cultural familiar con perturbaciones continuas que atraviesan la organización escolar. El horizonte de gestión se centra en la autoestima personal a través de una 'militancia' profesional con conocimientos complejos de tipo terapéutico. Una dirección colectiva que ejerce la animación comunitaria mediante la gestación de equipos y el emprendimiento innovador.

\section{Subtipo B.}

Se trata de un liceo de pequeña escala, barrial (zona con estrato socio-económico medio), con una población estudiantil homogénea.

El orden, la limpieza y el buen estado de conservación edilicia son premisas de la organización. Se constató un índice de infraestructura bueno y una adecuación a su finalidad y a la relación tamaño-alumnos.

Orientaciones y reglas precisas de conducta para las distintas actividades constituyen factores estructurantes y estabilizadores.

Un índice de equipamiento alto parece no asociarse a un índice de innovación pedagógico que evidenciamos como bajo (referido al uso de apoyaturas para el desarrollo del aprendizaje activo), lo que no favorecerla la promoción de procesos de cambio.

\section{Consideraciones Finales}

A través del análisis comparativo de ambos subtipos jerarquizamos.

- síndrome de pequeña escala como factor estructurante y estabilizador.

- ambiente simple (población estudiantil homogénea) y estable.

- intencionalidad de capitalizar fortalezas.

- el PEC. se manifiesta, en la opinión de los actores involucrados de cada centro, como una alternativa posible de implementar (subtipo A $87 \%$, subtipo B $54 \%$ ).

- valoración de la necesidad de participación e integración.

Por lo tanto, el PEC. constituye una alternativa real para ambos subtipos considerados. Además, consideramos que el tipo de gestión (pública-privada) no constituye una variable discriminante en lo referente a la viabilidad de un PEC.

\section{Conclusiones}

Considerando nuestro objetivo general y a partir del análisis comparativo de los modelos empíricos estudiados, formulamos conclusiones de carácter teórico-práctico que constituyen las alternativas de acción para la implementación del PEC.

Teniendo presente la problemática de la organización de cada uno de los subtipos de investigación estudiados, respetamos su identidad reconociendo en cada una de las alternativas planteadas diferentes

grados de afectación.

1.- Explicitación de contratos institucionales formalizados en términos como:

¿Qué se espera de mí en esta institución?

¿Cómo diseño mi proyecto pedagógico para el curso... en función de qué expectativas?

¿Qué espero de mis alumnos?

¿Cómo será evaluada mi tarea?

La explicitación del contrato institucional caracterizará la propuesta educativa de la institución, es decir, los términos en los que se define el vinculo de cada actor con la institución. 
2.- Resignificación de los espacios de coordinación formales, explicitando marcos teóricos y metodológicos, donde se ponderen intereses, expectativas y necesidades sin desconocer los márgenes de libertad de los actores para operar dentro de la institución. Se trata de implementar la dimensión organizacional-operativa a efectos de impulsar los procesos de participación e integ ración institucional.

3.- Especificación de tareas, funciones y responsabilidades que permitan articular la intervención coherente de acciones concretas y estrategias, abordando la multidimensionalidad de la organización escolar: la dimensión pedagógico-curricular, la dimensión comunitaria, la dimensión administrativa-financiera y la dimensión organizacional-operativa.

Este proceso de especificación se vería facilitado mediante la conformación de un grupo impulsor de proyecto representativo, idóneo y consensuado en su integración. Dicho grupo impulsor deberá encarar aspectos tales como: divulgación de documentación, relevamiento de opinión, resistencias y adhesiones indiscriminadas, realización de instancias de reflexión que permita reunir a los actores en equipos de trabajo.

4.- Refundación del contrato entre el centro educativo y la comunidad, valorando el atributo de especificidad de las instituciones (remitir tanto a saberes como a vínculos sociales).

Refundar el contrato escuela-comunidad en términos de un vínculo interactivo a través de los procesos de contextualización (proyectos curriculares), extensión (agente socializador), integración (comunidad de padres-instituciones locales). Esto requiere jerarquizar el vinculo de la dirección con los equipos docentes, instituyendo al Proyecto Educativo de Centro como una de las herramientas facilitadoras.

EI PEC generará condiciones aptas para que los sujetos tengan la oportunidad de crear, recrear, producir y aportar de manera consciente y eficaz, conocimientos, valores y procesos que hagan posible la construcción de un modelo educativo propio. 